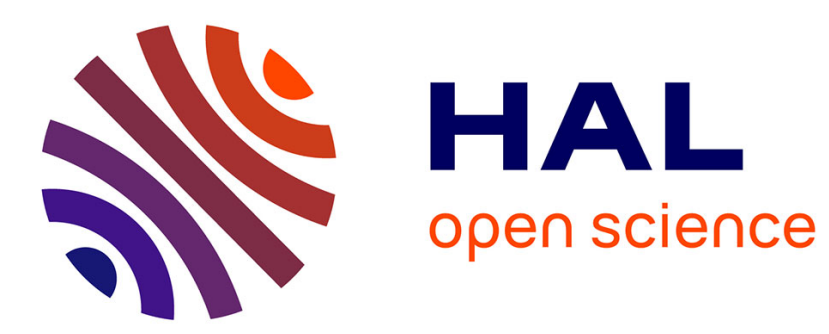

\title{
Broadband reflective liquid crystalline gels due to the ultraviolet light screening made by the liquid crystal
}

\author{
Sabrina Relaix, Christian Bourgerette, Michel Mitov
}

\section{To cite this version:}

Sabrina Relaix, Christian Bourgerette, Michel Mitov. Broadband reflective liquid crystalline gels due to the ultraviolet light screening made by the liquid crystal. Applied Physics Letters, 2006, 89 (25), pp.251907. 10.1063/1.2416251 . hal-03588664

\section{HAL Id: hal-03588664 https://hal.science/hal-03588664}

Submitted on 25 Feb 2022

HAL is a multi-disciplinary open access archive for the deposit and dissemination of scientific research documents, whether they are published or not. The documents may come from teaching and research institutions in France or abroad, or from public or private research centers.
L'archive ouverte pluridisciplinaire HAL, est destinée au dépôt et à la diffusion de documents scientifiques de niveau recherche, publiés ou non, émanant des établissements d'enseignement et de recherche français ou étrangers, des laboratoires publics ou privés. 


\title{
Broadband reflective liquid crystalline gels due to the ultraviolet light screening made by the liquid crystal
}

\author{
Sabrina Relaix, Christian Bourgerette, and Michel Mitov ${ }^{\text {a) }}$ \\ Centre d'Elaboration de Matériaux et d'Etudes Structurales (CEMES), CNRS, BP 94347, F-31055 Toulouse \\ Cedex 4, France
}

(Received 28 June 2006; accepted 14 November 2006; published online 19 December 2006)

\begin{abstract}
It is shown that the natural ultraviolet light absorbing properties of the liquid crystal constituent during the photoinduced elaboration of a liquid crystalline gel induce the broadening of the reflection bandwidth. The polymer component is then included in a resin by preserving its spatial distribution, and transmission electron microscopy investigations of cross sections show the existence of a structure gradient, which is at the origin of the broadening phenomenon. Such reflectors may be of interest for reflective polarizer-free displays or smart windows for the control of solar light for which a broadband reflection is required. (C) 2006 American Institute of Physics. [DOI: $10.1063 / 1.2416251]$
\end{abstract}

Reflective liquid crystal displays are interesting because they do not require a backlight source and polarizers-which absorb 50\% of the incident light, making possible more compact devices. ${ }^{1}$ Polymer-stabilized LCs (PSLCs) are currently investigated for this kind of application and, more generally, for flat-panel displays and switchable optical elements. PSLC are formed by dispersing a small percentage of photoreactive monomers into a low molar mass LC. ${ }^{2}$ After ultraviolet (UV) light exposure, a polymer network is formed and interdispersed throughout the LC component. As a consequence, the organization of the mesophase is transferred onto the structure of the network, the result of which is the salient feature of PSLCs.

Due to their helical structure, cholesteric LCs (CLCs) selectively reflect the light. ${ }^{3}$ When the incident light propagates essentially along the helical axis (i.e., when the CLC slab exhibits a planar Grandjean texture), a selective reflection occurs if the wavelength $\lambda_{0}$ is of the order of the pitch $p$ of the helix such that

$$
\lambda_{0}=n p \cos \theta,
$$

where $n$ is the average refractive index, $\left(n_{\|}+n_{\perp}\right) / 2\left(n_{\|}\right.$and $n_{\perp}$ are locally parallel and perpendicular to the director) and $\theta$ is the angle between the propagation direction and the helix axis. The reflection occurs within a bandwidth $\Delta \lambda$ $=\Delta n p \cos \theta$, where $\Delta n=n_{\|}-n_{\perp}$; outside this band, a CLC affects neither the amplitude nor the state of polarization of the transmitted light. Since $\Delta n$ values are limited to $0.3-0.4$ for colorless organic compounds, $\Delta \lambda$ is limited to a few tens of nanometers in the visible spectrum, which means that the CLC materials are effective for a certain color and not for the whole visible spectrum. For switchable reflective devicessuch as electro-optical glazing structures to be used for the dynamical controlling of the electromagnetic radiations-it is required to go beyond the usual limits of the reflection band of low molar mass CLCs. The choice of PSCLCs elaborated under specific ways has offered the opportunity to increase the wavelength reflection bandwidth. ${ }^{4-8}$ An earlier solution has consisted in the elaboration of a cholesteric

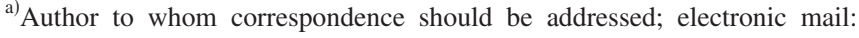
mitov@cemes.fr
}

layer with a pitch gradient. To produce such a structure, an UV light absorbing dye was used to create an intensity gradient through the thickness of a solid cholesteric polymer network ${ }^{9}$ or a switchable CLC gel. ${ }^{10}$ Therefore, the polymerization at the surface closest to the source is much faster than at the bottom of the layer. By blending a cholesteric diacrylate with a nematic (infinite-pitch cholesteric) monoacrylate, the former component has a twice as high probability than the nematic component to be incorporated into the polymer network; ${ }^{9}$ at low intensity, depletion of the chiral compound near the top of the cell generates a pitch gradient through the thickness of the layer. As a complementary possibility for going beyond the usual limits of the reflection band of low molar mass CLCs, the increase of the reflected light intensity-never greater than 50\% of ambient unpolarized light - may also be aimed, as recently demonstrated by using PSCLCs with a thermally induced inversion of the helicity sense. $^{11}$

The present work deals with the broadening of the reflection band of PSCLCs without the intervention of a foreign UV light absorbing dye but like the consequence of the natural absorbing properties of the LC constituent of the gel. We will highlight this phenomenon by using three different sets of irradiation conditions. Besides, after having succeeded in preserving the spatial distribution of the polymer network in the volume of the cell, we will investigate and compare the structure of cross sections of the network by transmission electron microscopy (TEM).

A room-temperature CLC (BL094 from Merck Ltd.) was mixed with bifunctional photoreactive nematic mesogens (RM257 from Merck Ltd.) at a concentration ratio of $91 \mathrm{wt} \%$ of LC/9 wt \% monomers, with a small amount of photoinitiator Irgacure 907 (from Ciba-Geigy; 2 wt \% compared to the RM257 amount). The blend is introduced at $83^{\circ} \mathrm{C}$ by capillarity in an $8 \mu \mathrm{m}( \pm 0.7 \mu \mathrm{m})$ thick indium tin oxide coated glass cell (from EHC Co. Ltd.; type FF). In order to induce a planar alignment, the surfaces have been treated with rubbed polyimide (the plates were assembled with their rubbing directions making an angle of $180{ }^{\circ} \mathrm{C}$ ). The cell was kept at room temperature and, for polymerization purposes, illuminated with UV light (centered at $365 \mathrm{~nm}$ and with a power equal to $0.1 \mathrm{~mW} / \mathrm{cm}^{2}$ ) for $30 \mathrm{~min}$; a black 


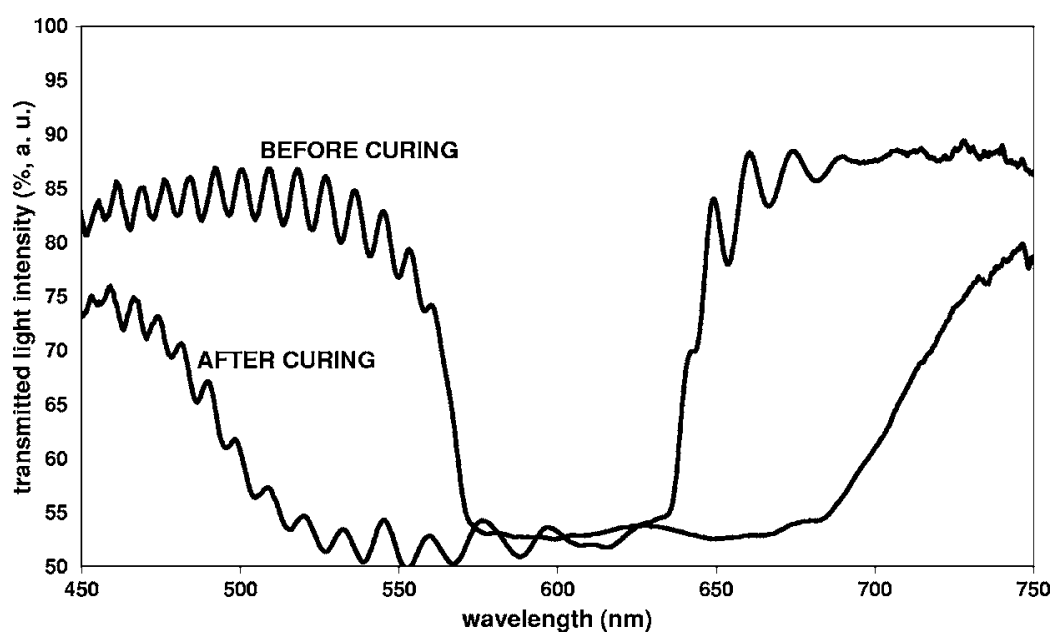

FIG. 1. Transmitted light intensity as a function of wavelength before and after ultraviolet light curing.

substrate was disposed under the cell. When observed by polarized optical microscopy in transmittance mode, the cell exhibits a well aligned reflective (planar) Grandjean texture with a moderate presence of oily streaks. Figure 1 shows the transmittance spectra of the cell before and after the photopolymerization. The spectra were recorded by using a HR2000CG-UV-near-infrared spectrophotometer (from Ocean Optics) associated with an optical microscope. All the base lines were recorded with air in the beam path. The incident light is unpolarized. Before curing, $\Delta \lambda$, as measured at the half-width of the peak, is about $80 \mathrm{~nm}$. After curing, the reflection bandwidth is approximately located at the same mean wavelength and has been significantly increased: $\Delta \lambda$ is now equal to about $220 \mathrm{~nm}$. This result was obtained under asymmetrical conditions for the irradiation. Since it is known that a broadening of the reflection band may arise from an intensity gradient, ${ }^{9}$ we investigated the role of a dual irradiation on the broadening property of the reflection bandwidth. We thus arranged a cell at half-distance between two sources. A power equal to $0.1 \mathrm{~mW} / \mathrm{cm}^{2}$ was measured on each plate of the sandwich cell. As shown in Fig. 2, the phenomenon of broadening of the reflection band is still present but less pronounced by comparison with the case of asymmetrical conditions: the reflection bandwidth is here equal to about $160 \mathrm{~nm}$ vs $220 \mathrm{~nm}$ in the former case.

The above results suggest that the broadening of the reflection band might be related to a concentration gradient in the polymer morphology from the up side of the cell-from which the light beam goes inside it-to the down one. A progressive absorption of UV light by the LC constituent may be suspected. We then decided to cure the experimental cell when a cell filled with the pure LC is attached to it on the up side. Such a geometry offers the opportunity to investigate the screening role of the LC constituent on the beam and, in return, the modification of the polymerization characteristics and the optical properties. Figure 3 shows the variation of the bandwidth with the thickness of the LC slab used like an UV light filter. $\Delta \lambda$ linearly decreases when the thickness increases: whereas $\Delta \lambda$ is about $220 \mathrm{~nm}$ when the curing occurs without filter, $\Delta \lambda$ decreases from 180 to $100 \mathrm{~nm}$ when the filter thickness changes from 4 to $44 \mu \mathrm{m}$. This result shows that the part of the incoming beam has been filtered by the LC cell and that the screening effect-from which a gradient network may arise-is strongly attenuated.

TEM investigations definitively offer the valuable opportunity to bring information about the structure of the polymer network in relation to the curing conditions and to give the visualization of the in situ distribution of a concentrationgradient polymer network in the volume of a PSLC. Resin is substituted for the LC component by immersing the gel cell in a bath of LR White resin diluted in a solvent (methanol); the concentration of resin in solvent is progressively increased from one step to the other one to optimize the filling of the network porosity. Such a modus operandi is expected to preserve the spatial distribution of the network into the cell volume. Finally, the cell is opened at room temperature; the material which consists of the polymer network embed-

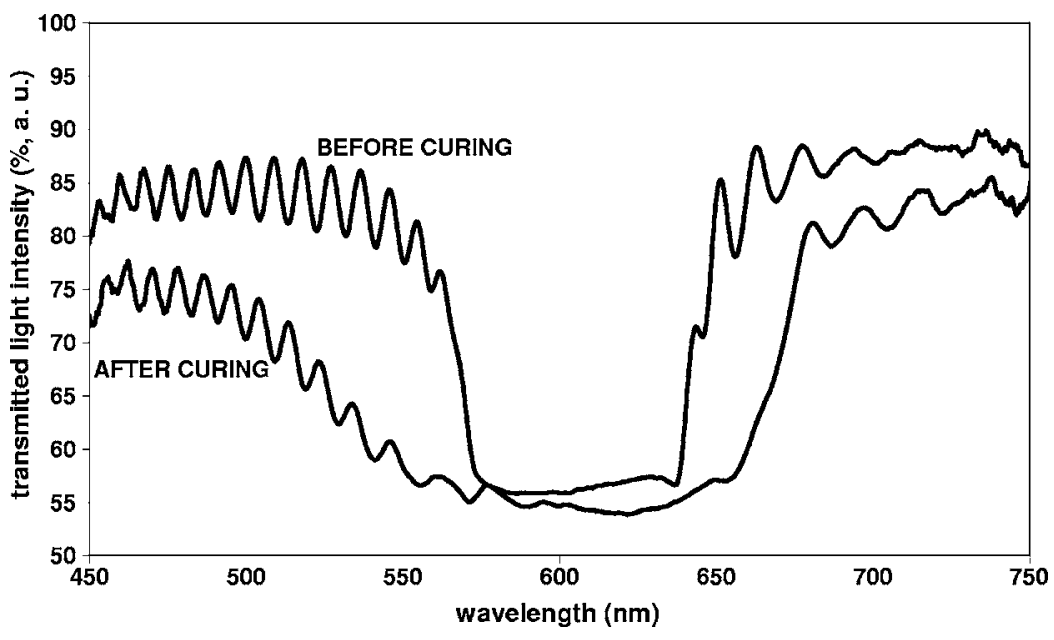

FIG. 2. Transmitted light intensity as a function of wavelength before and after ultraviolet light curing under symmetrical conditions. 


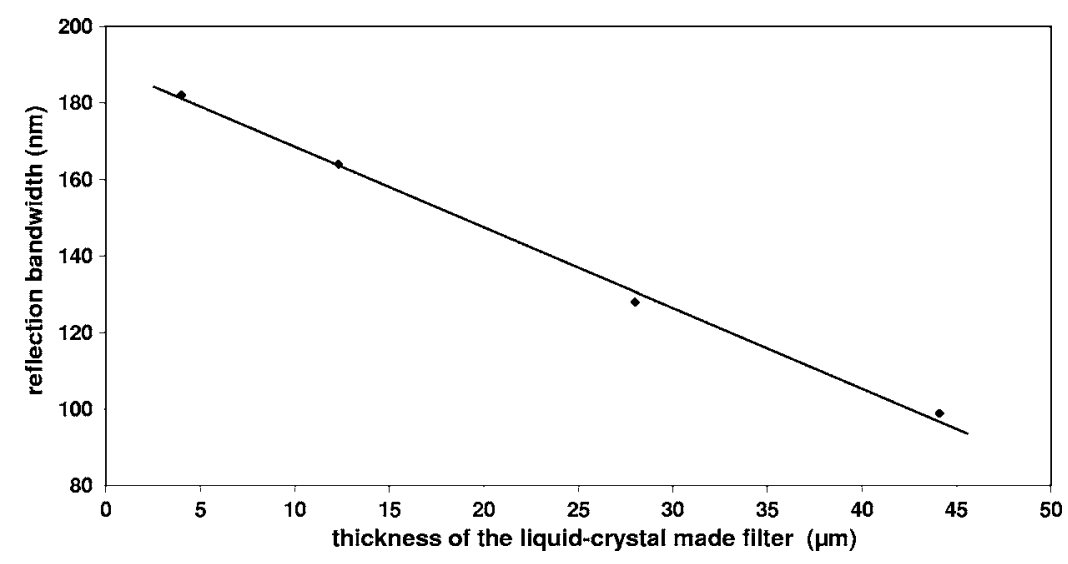

FIG. 3. Reflection wavelength bandwidth as a function of the thickness of the liquid crystal (BL094) filter attached to the cell during the ultraviolet light curing.

ded in a resin lump is removed and embedded in a second (epoxy) resin in order to be manipulated and cut during the microtomy process. $80 \mathrm{~nm}$ thick slices of cross sections of the sample are cut with an ultramicrotome (Reichert) at room temperature. The cuts are observed by TEM (Philips CM12 microscope). Figure 4 shows the micrographs of cross sections of the polymer when the gel was fabricated under asymmetrical [Fig. 4(a)] or symmetrical [Fig. 4(b)] conditions. Figure 4(a) clearly shows that the network is more concentrated close to the up side of the cell. A scattered network is displayed at the neighbor of the opposite side of the cell: this situation suggests that a discontinuous network, with oligomeric structures, is formed close to the down side. Therefore a concentration-gradient network has been formed in the LC volume when the curing conditions are asymmetrical. Under the hypothesis of a concentration gradient in the
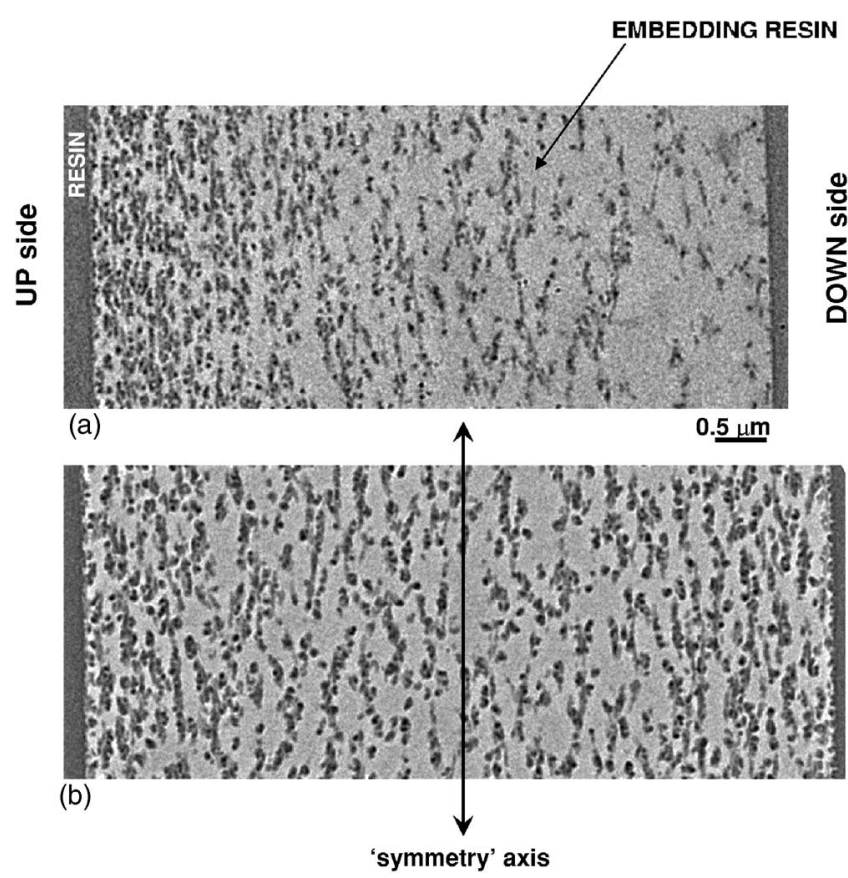

FIG. 4. Transmission electron micrographs of the polymer network embedded in a resin matrix, after dissolution of the LC, when the cell was irradiated (a) from one side or (b) simultaneously from both sides. polymer network like being at the origin of the pitch gradient, we can understand that this gradient is more modest when the symmetry conditions for the fabrication of the network in the LC volume are met and why a less broadened bandwidth is obtained in return. Indeed, Fig. 4(b) shows that the network morphology and distribution are qualitatively the same from one side to the other one by being symmetrical around the "symmetry" axis as reported in the picture. Interestingly, it has to be noticed that a discrete concentration gradient is still present from each one of the surfaces. In both cases, a local orientation of chains of polymer beads may be distinguished in a direction parallel to the surfaces but this kind of organization does not appear to be dense and regular whereas a periodic stratification reminiscent of the cholesteric fingerprint texture was observed in $25 \mu \mathrm{m}$ thick samples. $^{12}$

In view of practical applications, broadband reflective cholesteric gels may be of interest for reflective polarizerfree displays or for the light management for smart windows; the latter are electro-optical glazing structures, made with a cholesteric film sandwiched between glass panels, having reflective and transparent modes which are electrically switchable.

The authors are grateful to E. Nouvet for her help during the fabrication of cholesteric liquid crystal cells.

${ }^{1}$ S.-T. Wu and D.-K. Yang, Reflective Liquid Crystal Displays (Wiley, Singapore, 2001).

${ }^{2}$ For a monography, see Liquid Crystals in Complex Geometries, edited by G. P. Crawford and S. Zumer (Taylor \& Francis, London, 1996).

${ }^{3}$ P.-G. de Gennes and J. Prost, The Physics of Liquid Crystals, (Oxford University Press, Oxford, 1993), Vol. 83, pp. 264-268.

${ }^{4}$ N. Leroux, W. J. Fritz, J. W. Doane, and L.-C. Chien, Mol. Cryst. Liq. Cryst. Sci. Technol., Sect. A 261, 465 (1995).

${ }^{5}$ J.-F. Li, B. Fan, and L. Li, SID Int. Symp. Digest Tech. Papers 30, 1066 (1999).

${ }^{6}$ C. Binet, M. Mitov, and M. Mauzac, J. Appl. Phys. 90, 1730 (2001).

${ }^{7}$ H. Guillard and P. Sixou, Liq. Cryst. 28, 933 (2001).

${ }^{8}$ M. Mitov, E. Nouvet, and N. Dessaud, Eur. Phys. J. E 15, 413 (2004).

${ }^{9}$ D. J. Broer, J. Lub, and G. N. Mol, Nature (London) 378, 467 (1995).

${ }^{10}$ R. A. M. Hikmet and H. Kemperman, Nature (London) 392, 476 (1998).

${ }^{11}$ M. Mitov and N. Dessaud, Nat. Mater. 5, 361 (2006).

${ }^{12}$ S. Relaix, C. Bourgerette, and M. Mitov (unpublished). 